\title{
Investigating Saudi Parents' Intention to Adopt Technical Mediation Tools to Regulate Children's Internet Usage
}

\author{
Ala'a Bassam Al-Naim ${ }^{1}$, Md Maruf Hasan ${ }^{2}$ \\ Department of Information Systems \\ College of Computer Sciences and Information Technology \\ King Faisal University, Al Ahsa, Saudi Arabia
}

\begin{abstract}
The adverse and harmful effects of Internet on young children have become a global concern. Parents tend to use different strategies to ensure their children's online safety. Many studies have suggested that parental mediation may play a positive role in controlling children's online behavior. The purpose of this study is to identify the factors that shape Saudi parents' intention to regulate their children's online practices using technical mediation tools. An integrated model has been proposed based on famous Information System theories and models to investigate parental intention to adopt technical mediation tools. A questionnaire-based survey is conducted for data collection. Basic descriptive statistical analysis, reliability, and validity assessments were used to analyze the data at the preliminary stage, followed by advanced analysis using Structural Equation Modeling to test the research hypotheses. Research results indicate that effort expectancy, performance expectancy, general computer self-efficacy, perceived severity, and perceived vulnerability are the main predictors of Saudi parent's intention to regulate their children's online behaviors using technical mediation tools.
\end{abstract}

Keywords-Child and family safety online; parental control and mediation; technology mediation; Unified Theory of Acceptance and Use of Technology (UTAUT); Saudi Arabia

\section{INTRODUCTION}

Over the last decade, increased use of Internet has been observed worldwide. The Internet became an indispensable utility of our daily life serving multiple purposes such as personal development, education, entertainment, communication, harnessing information for better personal and professional decision-making, etc. Recent research shows that in developed countries it is a home based activity and current generation of young children cannot imagine a world without information and communication technologies (ICT), therefore, they are called digital natives [1]. Although Internet provides a powerful mean to access information and communicates with people to conduct useful activities, it possesses significant risk and threats for children and minors. There are evidences that use of Internet may expose young children to certain risks such as becoming victim of cyber bullying, negative emotional impacts due to unwanted exposure to pornography, violence, explicit language, revealing personal information to sexual predators etc. Since young children lack a sufficient level of ematurity to be able to manage these risks, some authors state that this generation is not only to be called "whiz kids" [2], but also "risk-kids" [3]. Therefore, the Internet impact on children and younger generation has become a global concern resulted in demands for safeguard to protect online privacy when involved with a wide variety of commercial websites and activities. Government in westerns countries is continuously engaged in implementing public policies, framework and legislation to reduce the unnecessary solicitation of personal information from children. One such example is Children's Online Privacy Protection Act (COPPA) implemented by U.S. Federal Trade Commission (FTC) which sets guidelines for online safeguards designed to prevent the collection of personally identifiable information from children unless parental consent is given [4].

However, as the media and communication environment quickly grow it becomes increasingly difficult for governments to formulate legal frameworks and enforce them. Policy makers rely substantially on increasing risk awareness among parents and delegating to them the responsibility for protecting children from online risks. Here the value of parental role becomes critical in view of safe Internet usage and Internet education. Active monitoring of children's online activities by parents can help guard children from the threats of the Internet. Parents implement a range of strategies, favoring active co-use and interaction rules over technical restrictions using filters or monitoring software. Active mediation involves parental guidance and advice through active discussions over online issues and staying nearby or sitting with children when they go online to monitor closely to reduce the likelihood of undesirable and damaging behaviors or attitudes.

However, parents find it increasing difficult to monitor their children actively as well as children don't like intense instructive. This results in development of huge number of technical filtering/monitoring tools and professional computer protection software's. However, studies on parents preferences [5] shows that although more than 75 per cent of parents were concerned about privacy risk and exposure to sexual content risk, only a smaller proportion of parents install filtering software (33 per cent) and monitoring software ( 23 per cent). Although technical mediation seems less instructive and allows more insight and control over the young Internet users. The main reason for not adopting technology is insufficient technical and Internet usage skills. 
It is more challenging when it comes to Saudi parents' context as compare to western world, due to huge cultural difference. The laws implemented in western countries are not acceptable in Saudi Arabia due to tight religion teaching. Furthermore, filtering and monitoring software could not directly implement in Saudi culture due to difference in social/religion norms. Since, what considered normal in western world might conflict with Islamic law. As a result, many sites were blocked at country level. When it comes to parent's level, most parents strictly banned their children to use internet and depriving them to get benefit of rich information content. On the other hand, if they allow their children to use Internet sufficient parental control strategies were not adopted, as a result their children are under constant online risk. There is a pressing need of educating Saudi parents to make them aware of using different technical tool to keep them safe. This main goal of the study is to identify factors that's determines Saudi parental intention to adopt technology mediation for safe Internet usage. Based preliminary on Protection Motivation Theory (PMT) [6], Unified Theory of Acceptance and Use of Technology (UTAUT) [7], and Technology Acceptance Model (TAM) combined with parental perspective an integrated model is proposed. Following main factors were investigated in proposed model to identify parents' acceptance of technology as mediation tool:

- Investigating Saudi patterns of parental mediation on children's online activities.

- Identify parent's awareness on severity of online risk.

- Level of parent's awareness of children internet usage.

- Parental level of internet and technology usage skills, level of comfort and easiness in using those skills.

- Exploring the Saudi parent's perception about technical mediation in providing the required protection for their children.

- Predicting parent's intention to adopt the technology to keep their children safe on Internet.

Rest of paper is organized as follow. Section II briefly explaining background of different parental mediation and highlighting technical mediation is least adopted. The proposed model and research method is presented in Sections III and IV. Research results are discussed in Section V. Finally, Section VI concludes the paper.

\section{RELATED WORK}

Internet impact on children and younger generation has become a global concern. The impact of parental involvement has been recognized in studies of media and children. In research dealing with television viewing term "mediation" is used as an effort to manage the relationships between the child and mass media [8]. Parents tend to use different strategies and practices to ensure that their children's usage of mass media such as TV, video games, and Internet [9] is under control. Two general mediation strategies have been identified in the context of interaction with mass media Active mediation and Restrictive mediation [10]. Active mediation consists of monitoring children media usage actively by sitting beside them and talking about media content while child is watching, reading, or listening the medium. Hence, instead of learning directly from environment they learn from their parents. In Restrictive mediation parents set limits for viewing or prohibit the viewing of certain content e.g. in context of TV setting number of hours a child can watch television or prohibit the viewing of a certain program or channel.

Do parents employ similar mediation strategies for the Internet? Some studies [9] stated that same strategies can be applied on internet usage. However, unlike other mass media internet is not shared activity. In addition, it is more interactive as compare to other media, so children are at highest risk. Therefore, parental awareness, and more comprehensive parental mediation strategies are requiring. Among actively monitoring their children and setting rules for internet usage there is a need certain tools to keep children safe online.

Green et al. [11] suggested technical based parental mediation by using parental control software settings for monitoring, filtering, and restricting unwanted contents. However, studies on parents preferences [5] shows only a smaller proportion of parents install filtering software (33 per cent) and monitoring software (23 per cent). Although technical mediation seems less instructive and allows more insight and control over young Internet users. Some studies concluded that using technical tools and settings is the least adopted type of mediation among other types [8], [12]. Besides that, most of parental mediation studies focused on other types of mediation strategies mentioned above while the technical type was partially or completely ignored [9], [13]. The literature did not provide a clear clue of why this type is the least adopted mediation style. Most studies mentioned the most and least used mediation styles with focusing on the most used ones and why they are being used mostly.

As we have explored personally some parental monitoring software and settings on different platforms, we believe in their ability to achieve what the normal styles could not. To fill the gap in current literature, it is important first to predict the reasons of why or why not a parent could think of adopting and accepting technical settings or software to regulate their children Internet usage. It has been observed from technology acceptance studies that the user intention is the main predictor of the usage behavior. These studies addressed the behavioral intention and its aspects in order to know how it can change the amount and tune of usage. The user intention to use a technology can be used to explore the amount of technology adoption or whether a person will use a technology or not [6], [14]. It has been observed from literature [8], [12], [15] that Europe and the US [6], [9], [18] is spending considerable amount of research in this area. When it comes to Saudi Arabia, it seems that Saudi researchers have entered this domain recently by Almoqbel et al. [16]. According to author they are first to study how Saudi parental educational and economic level's impact on their children internet usage habits. The aforementioned study is a social based research with narrow scope about the relationship among parent's specific demographics and mediation behavior. Above all, it seems that parental technical mediation topic was not covered enough by IS research papers. This study is first in Saudi context to explore different factors that can influence Saudi parents' 
intention to adopt technical mediation tools to regulate their children Internet usage.

In the next section, an integrated theoretical model is proposed and hypothesis was formulated to find relationship between different factors.

\section{RESEARCH MODEL AND HYPOTHESES}

Protection Motivation Theory (PMT) [6], Unified Theory of Acceptance and Use of Technology (UTAUT) [7], and Technology Acceptance Model (TAM) are selected as the reference to develop theoretical model for determining parents behavioral intention to adopt the technology as a mediation style. As shown in Fig. 1, proposed model contains six independent constructs, one dependent construct, and five moderators. The variables were either selected based on previous IS studies or self-constructed. Perceived Vulnerability (PV), Perceived Severity (PS), and Self Efficacy (SE) were selected from PMT. Whereas, Effort Expectancy (EE), and Performance Expectancy (PE) adopted from UTAT. Finally, Behavioral Intention was adopted from both UTAUT and TAM as a main indicator for accepting and using the technology. Furthermore, we have extended the model with self-constructed items such as Awareness of children online use [9, 17], Parent's Internet use [16], [18], Child Age [9], [13], [19], Educational level of Parents [16] , Gender of Parents [9], [15], [17] and Parents Age [7], [13], [15]. Details of constructs were presented in Table I.

TABLE I. CONSTRUCTS WiTH TheORETICAL DEFINITIONS

\begin{tabular}{|l|l|}
\hline \multicolumn{1}{|c|}{ Construct } & \multicolumn{1}{|c|}{ Theoretical Definition } \\
\hline $\begin{array}{l}\text { Behavioral Intention } \\
\text { (BI) }\end{array}$ & $\begin{array}{l}\text { Person's willingness and readiness to adopt } \\
\text { specific behavior [20, 21]. }\end{array}$ \\
\hline $\begin{array}{l}\text { Perceived Vulnerability } \\
\text { (PV) }\end{array}$ & $\begin{array}{l}\text { Person's evaluation of the possibility of } \\
\text { exposure to such threat [22]. }\end{array}$ \\
\hline Perceived Severity (PS) & $\begin{array}{l}\text { Measures the intensity of the consequences to a } \\
\text { person or others if the related threat increased } \\
\text { [23]. }\end{array}$ \\
\hline $\begin{array}{l}\text { Performance } \\
\text { expectancy (PE) }\end{array}$ & $\begin{array}{l}\text { The degree to which a person believes that using } \\
\text { a technology will help him to gain the benefits } \\
\text { he wants [20]. }\end{array}$ \\
\hline Effort Expectancy (EE) & $\begin{array}{l}\text { The level of easiness related to the use of a } \\
\text { technology [22]. }\end{array}$ \\
\hline $\begin{array}{l}\text { Awareness of children } \\
\text { online use (AW) }\end{array}$ & $\begin{array}{l}\text { Parents become aware about what their children } \\
\text { do online [9, 17] }\end{array}$ \\
\hline $\begin{array}{l}\text { General computer self- } \\
\text { efficacy (GCSE) }\end{array}$ & $\begin{array}{l}\text { Person's judgment of his ability and skills to any } \\
\text { task related to computer [24]. }\end{array}$ \\
\hline
\end{tabular}

Following hypotheses were constructed to examine proposed model of Saudi parent's intention to adopt technical mediation tools on children Internet usage.

H1: Perceived vulnerability of online risks for children will significantly predict the parent's intention

- H1a: Parent's Internet use will positively moderate the relationship between the perceived vulnerability of online risks for children and Saudi parent's intention.

- H1b: Child's age will negatively moderate the relationship between the perceived vulnerability of online risks for children and Saudi parent's intention.
- H1c: Parent's educational level will positively moderate the relationship between the perceived vulnerability of online risks for children and Saudi parent's intention.

H2: Perceived severity of online risks for children will significantly predict the Saudi parent's intention

H3: Performance expectancy will significantly predict the Saudi parent's intention

- H3a: Gender will positively moderate the relationship between the performance expectancy and parent's.

- H3b: Age will negatively moderate the relationship between the performance expectancy and parent's.

H4: Effort expectancy will significantly predict the parent's intention

- H4a: Gender will positively moderate the relationship between the effort expectancy and parent's intention.

- H4b: Age will negatively moderate the relationship between the effort expectancy and parent's intention.

H5: Parent's awareness of children online usage will significantly predict the parent's intention

- H5a: Parent's age will negatively moderate the relationship between the awareness of child's online activities and parent's intention.

H6: General computer self-efficacy will significantly predict the parent's intention

\section{RESEARCH METHODOLOGY}

\section{A. Instrument Development and Design}

In order to test research hypotheses, a survey questionnaire has been designed to collect the data from the targeted sample. The survey consists of 27 questions divided into three parts: First part is on parent's general information, second part is about child and his/her online usage, and third part contained question used to operationalize research hypothesis. Five point Lickert scale ranging from (1) strongly disagrees to (5) strongly agree and choice based measures are used to collect responses. Questionnaires were reviewed by three professors to check the face and content validity. We translated the questionnaire into Arabic to be appropriate for Saudi people. The translated survey with the original English was reviewed by graduate student from English language department. The goal was checking the validity of translation process. The Arabic version was presented to some parents ( 1 male and 2 female) to check the clarity of terminologies used.

Table II shows survey items for each construct along with supporting studies.

\section{B. Tools and Techniques}

Two quantitative approaches were used to analyze the collected data. First, demographic data is analyzed via descriptive statistics using Statistical Package for Social Sciences (SPSS). Second, WarpPLS 5.0 [25] is used to assess the reliability, validity as well as hypothesis testing. Structural Equation Modeling (SEM) was used for hypothesis testing. 


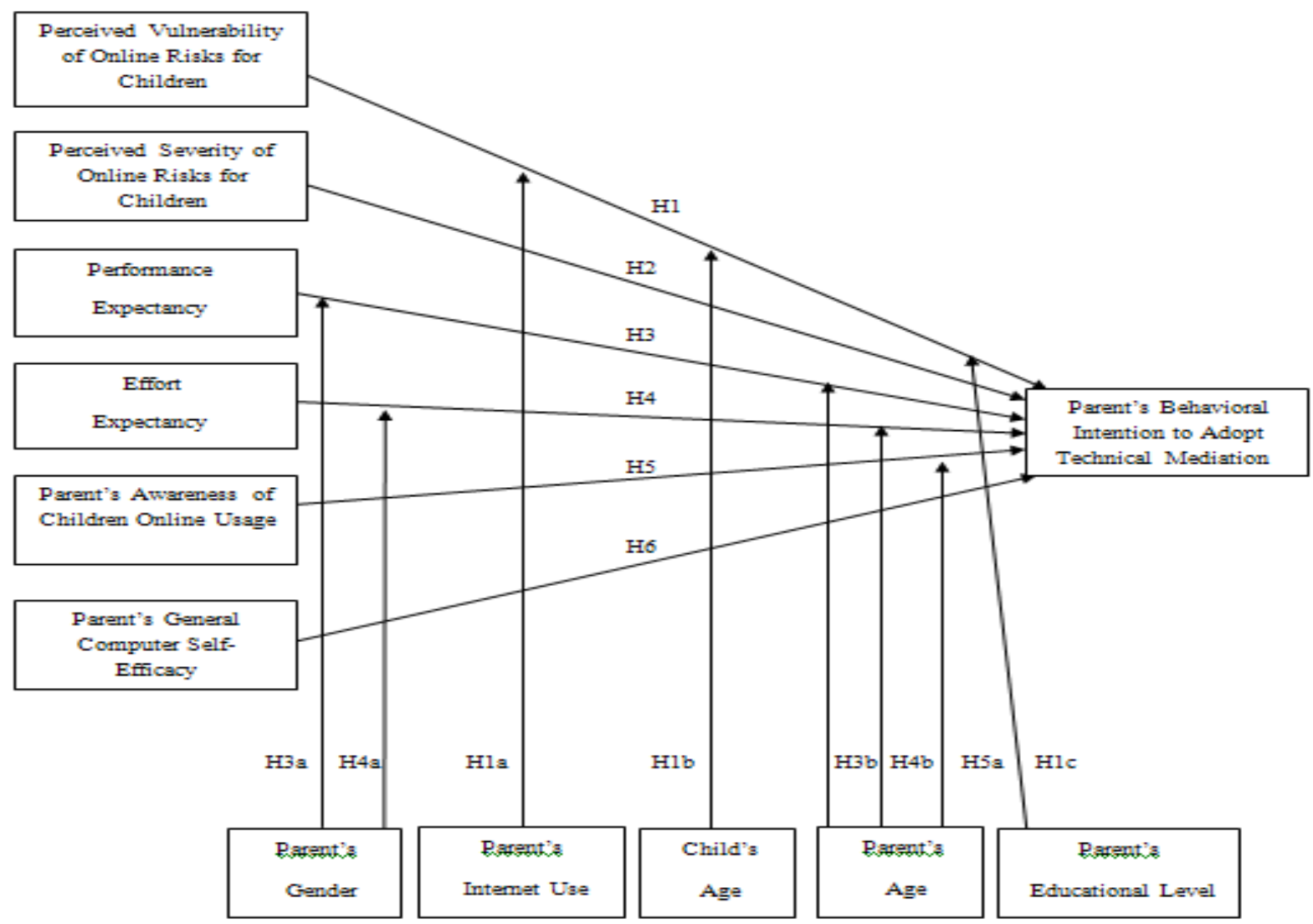

Fig. 1. Research hypothesized model.

TABLE II. CONSTRUCTS AND SURVEY ITEMS

\begin{tabular}{|l|l|}
\hline Construct & Survey Items \\
\hline \multirow{5}{*}{ BI [26] } & $\begin{array}{l}\text { BI1: I will adopt technical mediation to regulate my child } \\
\text { Internet usage. }\end{array}$ \\
\cline { 2 - 3 } & $\begin{array}{l}\text { BI2: What are the chances in 100 that you will adopt } \\
\text { technical mediation to regulate your child Internet usage. }\end{array}$ \\
\cline { 2 - 3 } & $\begin{array}{l}\text { BI3: To regulate my child's Internet usage, I would adopt } \\
\text { technical mediation rather than any other means available. }\end{array}$ \\
\hline \multirow{5}{*}{ PV [6] } & PV1: My children are exposed to one or more online risks. \\
\cline { 2 - 3 } & $\begin{array}{l}\text { PV2: It is likely that my children will be exposed to one or } \\
\text { more online risks. }\end{array}$ \\
\cline { 2 - 3 } & $\begin{array}{l}\text { PV3: It is possible that my children will be exposed to one or } \\
\text { more online risks. }\end{array}$ \\
\hline \multirow{5}{*}{ PE [27] } & $\begin{array}{l}\text { PS1: I believe that my child's exposure to one or more online } \\
\text { risks would be a severe problem. }\end{array}$ \\
\cline { 2 - 3 } & $\begin{array}{l}\text { PS2: I believe that my child's exposure to one or more online } \\
\text { risks would be a serious problem. }\end{array}$ \\
\cline { 2 - 3 } & $\begin{array}{l}\text { PS3: I believe that my child's exposure to one or more online } \\
\text { risks would be a significant problem. }\end{array}$ \\
\hline \multirow{5}{*}{ EE [27] } & $\begin{array}{l}\text { PE1: I find using parental monitoring software or parental } \\
\text { control settings will be useful in my mediation. }\end{array}$ \\
\cline { 2 - 3 } & $\begin{array}{l}\text { Using parental monitoring software or PE2: Parental control } \\
\text { settings will enable me to accomplish the mediation task } \\
\text { more quickly. }\end{array}$ \\
\cline { 2 - 3 } & $\begin{array}{l}\text { PE3: Using parental monitoring software or parental control } \\
\text { settings will enhance more online safety for my children. }\end{array}$ \\
\hline & $\begin{array}{l}\text { EE1: It will be easy for me to become skillful at using } \\
\text { parental monitoring software or parental control settings to } \\
\text { regulate my child's Internet usage. }\end{array}$ \\
\cline { 2 - 3 } & $\begin{array}{l}\text { EE2: I find that parental monitoring software or parental } \\
\text { control settings will be easy to use for mediating my child's }\end{array}$ \\
\hline &
\end{tabular}

\begin{tabular}{|l|l|}
\hline \multirow{5}{*}{$\begin{array}{l}\text { AW (Self- } \\
\text { Constructed) }\end{array}$} & $\begin{array}{l}\text { Internet usage. } \\
\text { EE3: Learning to use parental monitoring software or } \\
\text { parental control settings to regulate my child's Internet usage }\end{array}$ \\
\cline { 2 - 3 } AW1: I know exactly what does my child do online. \\
\cline { 2 - 2 } & $\begin{array}{l}\text { AW2: I know exactly how much time my child spends } \\
\text { online. }\end{array}$ \\
\hline & $\begin{array}{l}\text { GCSE1: I believe I have the ability to unpack and set up a } \\
\text { new computer. }\end{array}$ \\
\cline { 2 - 3 } GCSE [28] & $\begin{array}{l}\text { GCSE2: I believe I have the ability to install new software } \\
\text { applications on a computer. }\end{array}$ \\
\cline { 2 - 3 } & $\begin{array}{l}\text { GCSE3: I believe I have the ability to use a computer to } \\
\text { display or present information in a desired manner. }\end{array}$ \\
\cline { 2 - 3 } & $\begin{array}{l}\text { GCSE4: I believe I have the ability to identify and correct } \\
\text { common operational problems with a computer. }\end{array}$ \\
\cline { 2 - 3 } & $\begin{array}{l}\text { GCSE5: I believe I have the ability to remove information } \\
\text { from a computer that I no longer need. }\end{array}$ \\
\hline
\end{tabular}

\section{Demographic Characteristics}

Data was collected both by means of an online platform and in person by distributing copies. The total number of responses collected were 196 out of 280 copies which shows $70 \%$ response rate. Total 55 responses were collected online, hence total number of responses for both paper based and online was 251. Table III shows the general characteristics of respondents. Majority of respondents were females with percentage of $(61.4 \%)$. Statistics also show that $(76.5 \%)$ of respondents were university graduates and $(59.4 \%)$ were using the Internet frequently. The descriptive statistics of the participants' responses are presented in Table IV. 
TABLE III. GENERAL CHARACTERISTICS OF THE SAMPLE

\begin{tabular}{|c|c|c|c|}
\hline Measure & Item & Frequency & Percentage \\
\hline \multirow{2}{*}{$\begin{array}{l}\text { Parent's } \\
\text { gender }\end{array}$} & Male & 97 & $38.6 \%$ \\
\hline & Female & 154 & $61.4 \%$ \\
\hline \multirow{4}{*}{ Parent's age } & $25-35$ years & 119 & $47.4 \%$ \\
\hline & $36-46$ years & 91 & $36.3 \%$ \\
\hline & $47-57$ years & 40 & $15.9 \%$ \\
\hline & Over 57 years & 1 & $0.4 \%$ \\
\hline \multirow{6}{*}{$\begin{array}{l}\text { Educational } \\
\text { level }\end{array}$} & Illiterate & 0 & $0 \%$ \\
\hline & Elementary & 1 & $0.4 \%$ \\
\hline & Intermediate & 9 & $3.6 \%$ \\
\hline & Secondary & 33 & $13.1 \%$ \\
\hline & $\begin{array}{l}\text { University } \\
\text { graduate }\end{array}$ & 192 & $76.5 \%$ \\
\hline & $\begin{array}{l}\text { Postgraduate } \\
\text { (PhD or } \\
\text { Master) }\end{array}$ & 16 & $6.4 \%$ \\
\hline \multirow{4}{*}{$\begin{array}{l}\text { Parent's } \\
\text { Internet use }\end{array}$} & Frequently & 149 & $59.4 \%$ \\
\hline & Occasionally & 92 & $36.6 \%$ \\
\hline & Rarely & 9 & $3.6 \%$ \\
\hline & Never & 1 & $0.4 \%$ \\
\hline \multirow{4}{*}{ Child's Age } & $6-7$ years & 82 & $32.7 \%$ \\
\hline & $8-9$ years & 58 & $23.1 \%$ \\
\hline & $10-11$ years & 58 & $23.1 \%$ \\
\hline & $12-13$ years & 53 & $21.1 \%$ \\
\hline
\end{tabular}

\section{DATA ANALYSIS AND RESULTS}

Two types of quantitative approaches were used to analyze the collected data. First, reliability and validity of the questionnaire is estimated to determine the adequacy of measuring items. Second, SEM is built to test whether proposed hypothesis are supported by data or not.

\section{A. The Assessment of the Measurement Model}

Model reliability, Convergent and Discriminant validity [29] is examined to identify the adequacy of measurement model. Construct validity is defined as the degree to which the operational measurement actually reflects the true theoretical meaning of a concept/construct [30]. It was conducted through calculating composite reliability and Average Variance Extracted (AVE) for each latent construct. For a construct, the convergent validity is achieved when it scores a composite reliability above 0.70 and AVE value above 0.50 [31]. Table V shows the results of convergent validity assessment where all constructs reported composite reliability values greater than 0.70 and AVE values greater than 0.50 . Discriminant validity was assessed through calculating the square root of AVE for each latent construct and comparing it with the intercorrelations among model constructs. As shown in Table VI, the square root values for each latent construct are exceeded all its correlations with other constructs in the model and so the discriminant validity requirements were met.

TABLE IV. CONVERGENT VALIDITy STATISTICS

\begin{tabular}{|l|l|l|}
\hline Construct & $\begin{array}{l}\text { Composite } \\
\text { Reliability }\end{array}$ & AVE \\
\hline PV & 0.877 & 0.704 \\
\hline PS & 0.911 & 0.774 \\
\hline PE & 0.909 & 0.768 \\
\hline EE & 0.903 & 0.756 \\
\hline AW & 0.785 & 0.647 \\
\hline GCSE & 0.860 & 0.553 \\
\hline BI & 0.816 & 0.597 \\
\hline
\end{tabular}

TABLE V. DISCRIMINANT VALIDITY STATISTICS

\begin{tabular}{|l|l|l|l|l|l|l|l|}
\hline & PV & PS & PE & EE & AW & GCSE & BI \\
\hline PV & $\mathbf{0 . 8 3 9}$ & & & & & & \\
\hline PS & 0.470 & $\mathbf{0 . 8 7 9}$ & & & & & \\
\hline PE & 0.167 & 0.225 & $\mathbf{0 . 8 7 6}$ & & & & \\
\hline EE & 0.074 & 0.215 & 0.541 & $\mathbf{0 . 8 6 9}$ & & & \\
\hline AW & 0.095 & 0.156 & 0.088 & 0.047 & $\mathbf{0 . 8 0 4}$ & & \\
\hline GCSE & 0.050 & 0.196 & 0.166 & 0.315 & 0.172 & $\mathbf{0 . 7 4 3}$ & \\
\hline BI & 0.133 & 0.247 & 0.513 & 0.620 & 0.020 & 0.290 & $\mathbf{0 . 7 7 2}$ \\
\hline
\end{tabular}

Cronbach's coefficient alpha (CA) was calculated to examine the internal consistency for each construct. The results are presented in the Table VII. Generally, all constructs reported appropriate reliability values above 0.70 except behavioral intention (BI) and parent's awareness of child's Internet usage (AW) which scored 0.662 and 0.453 respectively. Therefore, we have used the statistical resampling of data to generate simulated data and re-examine the reliability of constructs. Results have shown that all constructs scored composite reliability coefficients above the critical threshold value of 0.70 [32].

TABLE VI. RELIABILITY STATISTICS FOR RESEARCH MODEL

\begin{tabular}{|l|l|l|l|}
\hline Construct & $\begin{array}{l}\text { No. Of } \\
\text { Items }\end{array}$ & $\begin{array}{l}\text { Cronbach's } \\
\text { Alpha }\end{array}$ & $\begin{array}{l}\text { Composite } \\
\text { Reliability }\end{array}$ \\
\hline PV & 3 & 0.788 & 0.877 \\
\hline PS & 3 & 0.854 & 0.911 \\
\hline PE & 3 & 0.849 & 0.909 \\
\hline EE & 3 & 0.839 & 0.903 \\
\hline AW & 2 & 0.453 & 0.785 \\
\hline GCSE & 5 & 0.795 & 0.860 \\
\hline BI & 3 & 0.662 & 0.816 \\
\hline
\end{tabular}

\section{B. The Assessment of the Structural Model}

The structural model is evaluated and hypothesis is tested after establishing adequacy of measurement model. SEM is most commonly used multivariate technique [33] for instrument validation and model testing to identify series of relationship constitutes in large-scale model or an entire theory. Following coefficients are calculated to assess SEM: P values (probabilities), path coefficients (Beta coefficients), and $\mathrm{R}^{2}$ (explanatory variance power). The results indicate clearly which hypotheses were supported and which of them were not based on $\mathrm{P}$ values and Beta coefficients. If the beta coefficient was positive (in the right direction) and the probability value was significant (below one of critical thresholds: 0.05, 0.01, or 0.001 ), the hypothesis will be supported. In this study, we compared the $\mathrm{p}$ values to the three levels of significance 
following what has been done by S. Al-Gahtani et al. [32]. $\mathrm{R}^{2}$ is goodness-of-fit measurement that shows how the behavior of dependent construct is controlled by the behavior of independent construct. It acts as a descriptive or explanatory power of the model to explain the study constructs [34]. As high the $\mathrm{R}^{2}$ value of the model is as it has high descriptive power.

\section{Hypotheses Testing Results}

Hypotheses testing results for the hypothesized model are illustrated in Fig. 2 and explained clearly in Table VII. The results of hypotheses testing are reported as follows:

- H1 $(\mathrm{PV} \rightarrow \mathrm{BI})$ Perceived vulnerability of online risks for children significantly predicts the Saudi parent's intention to adopt technical mediation tools on children Internet usage. This hypothesis is supported (Beta = $\left.0.133, \mathrm{P}^{*}=0.036<0.05\right)$.

- H2 $(\mathrm{PS} \rightarrow \mathrm{BI})$ : Perceived severity of online risks for children significantly predicts the Saudi parent's intention to adopt technical mediation tools on children Internet usage. This hypothesis is supported (Beta $=$ $0.247, \mathrm{P} * * *<0.001)$.

- H3 (PE $\rightarrow \mathrm{BI})$ : Performance expectancy significantly predicts the Saudi parent's intention to adopt technical mediation tools on children Internet usage. This hypothesis is supported (Beta $\left.=0.513, \mathrm{P}^{* * *} * 0.001\right)$.

- H4 (EE $\rightarrow \mathrm{BI})$ : Effort expectancy significantly predicts the Saudi parent's intention to adopt technical mediation tools on children Internet usage. This hypothesis is supported (Beta $\left.=0.620, \mathrm{P}^{* * *} * 0.001\right)$.

- H5 (AW $\rightarrow \mathrm{BI})$ : Saudi parent's awareness of children online usage does not predict the Saudi parent's intention to adopt technical mediation tools on children Internet usage. This hypothesis is not supported (Beta $=$ $0.020, \mathrm{P}=0.750)$.

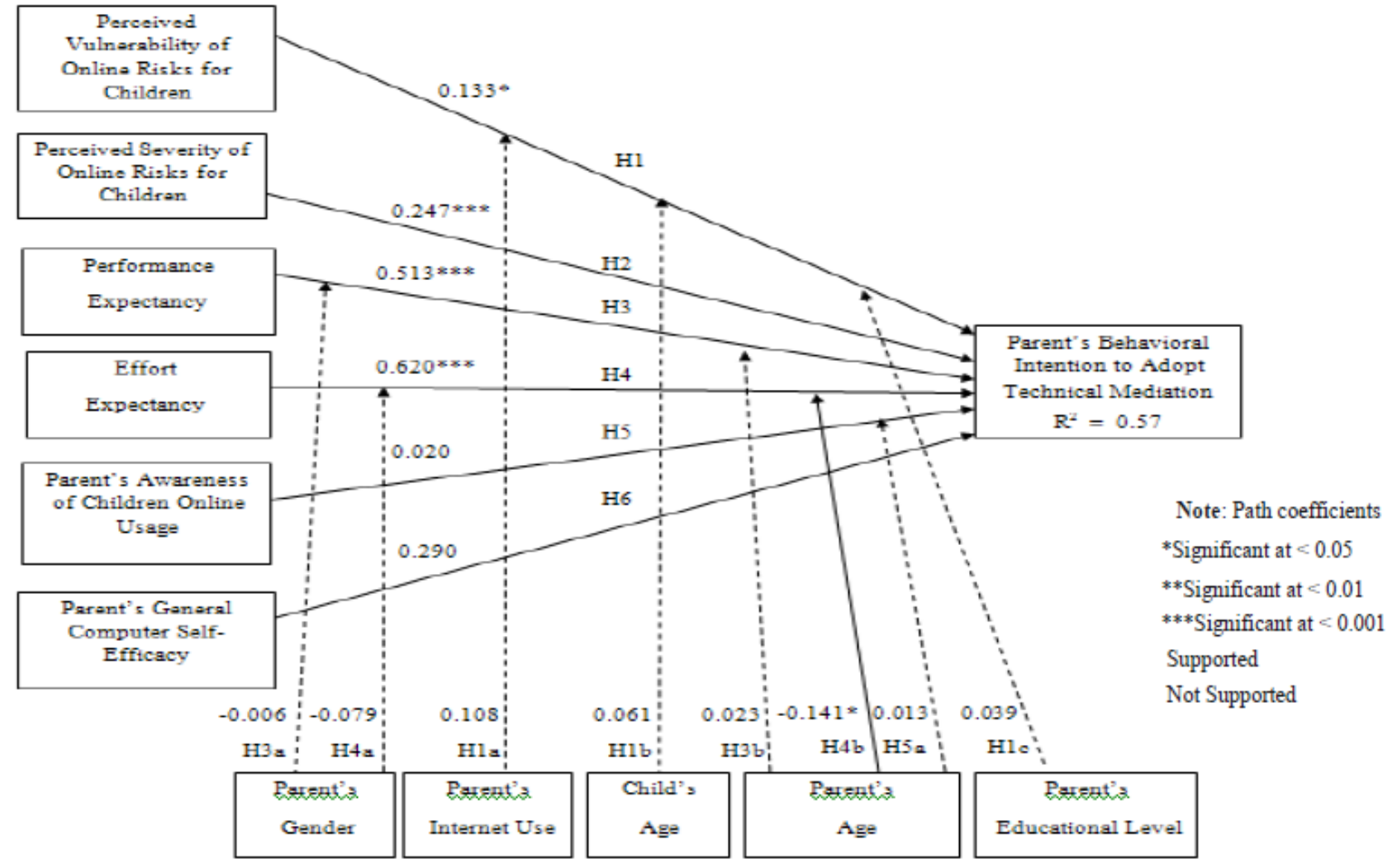

Fig. 2. Research model hypotheses results.

- HH6 (GCSE $\rightarrow$ BI): Saudi parent's general computer self-efficacy significantly predicts the Saudi parent's intention to adopt technical mediation tools on children Internet usage. This hypothesis is supported (Beta = $0.290, \mathrm{P} * * *<0.001)$.

- H1a (P_IU $\rightarrow$ H1): Saudi parent's Internet use does not moderate the relationship between the perceived vulnerability of online risks for children and Saudi parent's intention to adopt technical mediation tools on children Internet usage positively. This hypothesis is not supported $($ Beta $=0.108, \mathrm{P}=0.086)$.

- H1b $\left(\mathrm{C}_{-}\right.$Age $\left.\rightarrow \mathrm{H} 1\right)$ : Child's age does not moderate the relationship between the perceived vulnerability of online risks for children and Saudi parent's intention to adopt technical mediation tools on children Internet usage negatively. This hypothesis is not supported (Beta $=0.061, \mathrm{P}=0.335$ ). 
- H1c (P_Edu $\rightarrow$ H1): Saudi parent's educational level does not moderate the relationship between the perceived vulnerability of online risks for children and Saudi parent's intention to adopt technical mediation tools on children Internet usage positively. This hypothesis is not supported (Beta $=0.039, \mathrm{P}=0.538)$.

- H3a (P_Gende $\rightarrow$ H3): Saudi parent's gender does not moderate the relationship between the performance expectancy and Saudi parent's intention to adopt technical mediation tools on children Internet usage positively. This hypothesis is not supported (Beta $=$ $0.006, \mathrm{P}=0.920$ ).

- H3b (P_Age $\rightarrow$ H3): Saudi parent's age does not moderate the relationship between the performance expectancy and Saudi parent's intention to adopt technical mediation tools on children Internet usage negatively. This hypothesis is not supported (Beta $=$ $0.023, \mathrm{P}=0.713$ ).

- H4a (P_Gender $\rightarrow$ H4): Saudi parent's gender does not moderate the relationship between the effort expectancy and Saudi parent's intention to adopt technical mediation tools on children Internet usage positively. This hypothesis is not supported $($ Beta $=-0.079, \mathrm{P}=$ 0.211 )

- H4b (P_Age $\rightarrow$ H4): Saudi parent's age moderates the relationship between the effort expectancy and Saudi parent's intention to adopt technical mediation tools on children Internet usage negatively. This hypothesis is supported $\left(\right.$ Beta $\left.=-0.141, \mathrm{P}^{*}=0.026<0.05\right)$.

- H5a (P_Age $\rightarrow$ H5): Saudi parent's age does not moderate the relationship between the awareness of child's online activities and Saudi parent's intention to adopt technical mediation tools on children Internet usage negatively. This hypothesis is not supported (Beta $=0.013, \mathrm{P}=0.843$ ).

For $\mathrm{R}$ squared coefficient, note that each independent variable accounts $57 \%$ of the explanatory variance toward BI. In total, the hypothesized model explains $57 \%$ of the explanatory variances for BI.

TABLE VII. RESEARCH MODEL HYPOTHESES RESULTS

\begin{tabular}{|c|c|c|c|c|}
\hline Hypotheses & $\begin{array}{c}\text { Beta } \\
\text { value }\end{array}$ & $P$ value & $\mathbf{R}^{2}$ & Conclusion \\
\hline $\mathrm{H} 1(\mathrm{PV} \rightarrow \mathrm{BI})$ & 0.133 & $\begin{array}{l}0.036 \\
\mathrm{P}^{*}<0.05\end{array}$ & $57 \%$ & Supported \\
\hline $\mathrm{H} 2(\mathrm{PS} \rightarrow \mathrm{BI})$ & 0.247 & $\mathrm{P}^{* * *}<0.001$ & $57 \%$ & Supported \\
\hline $\mathrm{H} 3(\mathrm{PE} \rightarrow \mathrm{BI})$ & 0.513 & $\mathrm{P}^{* * *}<0.001$ & $7 \%$ & Supported \\
\hline $\mathrm{H} 4(\mathrm{EE} \rightarrow \mathrm{BI})$ & 0.620 & $\mathrm{P}^{* * *}<0.001$ & $7 \%$ & Supported \\
\hline $\mathrm{H} 5(\mathrm{AW} \rightarrow \mathrm{BI})$ & 0.020 & 0.750 & $57 \%$ & Non supported \\
\hline H6 (GCSE $\rightarrow$ BI) & 0.290 & $\mathrm{P} * * *<0.001$ & $57 \%$ & Supported \\
\hline H1a $($ P_IU $\rightarrow$ H1) & 0.108 & 0.086 & N/A & Non supported \\
\hline $\mathrm{H} 1 \mathrm{~b}\left(\mathrm{C} \_\right.$Age $\left.\rightarrow \mathrm{H} 1\right)$ & 0.061 & 0.335 & N/A & Non supported \\
\hline H1c $($ P_Edu $\rightarrow$ H1) & 0.039 & 0.538 & N/A & Non supported \\
\hline H3a $($ P_Gender $\rightarrow$ H3) & -0.006 & 0.920 & N/A & Non supported \\
\hline $\mathrm{H} 3 \mathrm{~b}\left(\mathrm{P} \_\right.$Age $\left.\rightarrow \mathrm{H} 3\right)$ & 0.023 & 0.713 & N/A & Non supported \\
\hline H4a $($ P_Gender $\rightarrow$ H4) & -0.079 & 0.211 & N/A & Non supported \\
\hline $\mathrm{H} 4 \mathrm{~b}\left(\mathrm{P} \_\right.$Age $\left.\rightarrow \mathrm{H} 4\right)$ & -0.141 & $\begin{array}{l}0.026 \\
* \mathrm{P}<0.05\end{array}$ & N/A & Supported \\
\hline H5a $\left(\mathrm{P}_{-}\right.$Age $\rightarrow$ H5) & 0.013 & 0.843 & N/A & No supported \\
\hline
\end{tabular}

\section{CONCLUSION AND IMPLICATIONS OF THE STUDY}

Internet technology is continuously evolving leaving the parents worry regard its hidden threats and dangers on their children. By mediating them appropriately, parents can promote a safe online environment for their children. Different regulation strategies have appeared to apply more control on child's Internet use. This survey- based study has investigated the factors that shape the intention to use these tools in regulating Internet use of children in Saudi Arabia. Our study found that the main predictors are perceived vulnerability, perceived severity, performance expectancy, effort expectancy, and general computer self-efficacy. Effort expectancy was found as the most powerful predictor while the perceived vulnerability was the least powerful one. The hypothesis regarding parent's age and effort expectancy was supported among the other moderating variables. Child and family safety domain is still considered young in Saudi context. This domain needs to be enriched with serious efforts from both public and private sectors. Saudi researchers, programmers, and educators need to work together to raise the Saudi public awareness on how to employ the Internet as an useful and harmless tool. We 
envisage that software designed and developed based on this research finding will accommodate effective parental mediation and ensure child and family safety. This study provides the following significant implications:

- Effort expectancy and performance expectancy were found as the most powerful predictors of behavioral intention to use technical mediation. Popular protection software vendors need to understand and shape the different needs of different users. Most of these parental software do not support the Arabic language in its settings, considering the language is important for Saudi parents to make their interaction with software easier since most of them do not talk the English.

- Also, a clear absence of Arabic parental protection software in the market was observed, Arabic developers can benefit from the current research to predict how to attract the public through designing simple fullyfunctional software; e.g. we found that parents thought about the software abilities to provide their children with the required online protection. This result may inspire the developers to add good protective features.

- The current findings may inspire other researchers to test this model on different contexts and bigger sample sizes.

- The findings could also help those educators or people working in social awareness organizations to design awareness tools to aware the parents of the importance of technology in saving their children online.

- The research is presenting $\mathrm{R} 2$ as goodness-of-fit measure which has scored more than $50 \%$ among the results.

- Further research could be done by considering and testing other factors like social influence or financial barriers which could increase the model explanatory power.

- The model drives its power from known IS models and theories like PMT and TAM as it borrows some of their constructs.

\section{ACKNOWLEDGMENTS}

This research was supported by the Master of Science in Computer Information System (MS-CIS) program at the Colleges of Computer Sciences and Information Technology, at King Faisal University. The authors like to thank Dr. Shaheen Khatoon and Dr. Majed Alshamari for their useful comments and feedback over two semesters as members of the supervisory committee. They are also indebted to Dr. Mohamed Elhassan for his generous help with the model development and verification as well as the data analysis and software support.

\section{REFERENCES}

[1] M. Prensky, "Digital Natives, Digital Immigrants Part II. Do they really think differently? Retrieved 14 May 2008," On the Horizon, vol. 9, pp. 19, 2001.
[2] S.-J. Lee and Y.-G. Chae, "Children's Internet use in a family context: Influence on family relationships and parental mediation," CyberPsychology \& Behavior, vol. 10, pp. 640-644, 2007.

[3] G. Kuipers, "The social construction of digital danger: debating, defusing and inflating the moral dangers of online humor and pornography in the Netherlands and the United States," New Media \& Society, vol. 8, pp. 379-400, 2006.

[4] COPPA. (1998). Children's Online Privacy Protection Act. Available: http://www.ftc.gov/ogc/coppa1.htm

[5] J. Turow and L. Nir, "The Internet and the family: The view of US parents," Children in the new media landscape, pp. 331-348, 2000.

[6] R. E. Crossler, "Protection motivation theory: Understanding determinants to backing up personal data," presented at the System Sciences (HICSS), 2010 43rd Hawaii International Conference on, 2010.

[7] A. A. Taiwo and A. G. DOWNE, "THE THEORY OF USER ACCEPTANCE AND USE OF TECHNOLOGY (UTAUT): A METAANALYTIC REVIEW OF EMPIRICAL FINDINGS," Journal of Theoretical \& Applied Information Technology, vol. 49, 2013.

[8] R. Hechanova and R. Ortega-Go, "The Good, the Bad and the Ugly: Internet Use, Outcomes and the Role of Regulation in the Philippines," The Electronic Journal of Information Systems in Developing Countries, vol. 63, 2014.

[9] S. N. Hamade, "Parental Awareness and Mediation of Children's Internet Use in Kuwait," presented at the Information Technology-New Generations (ITNG), 2015 12th International Conference on, 2015.

[10] A. I. Nathanson, "Parent and child perspectives on the presence and meaning of parental television mediation," Journal of Broadcasting \& Electronic Media, vol. 45, pp. 201-220, 2001.

[11] L. Green, D. Brady, K. Ólafsson, J. Hartley, and C. Lumby, "Risks and safety for Australian children on the internet," Cultural Science Journal, vol. 4, 2011.

[12] A. Duerager and S. Livingstone, "How can parents support children's internet safety?," EUKids Online, 2013.

[13] M. Valcke, S. Bonte, B. De Wever, and I. Rots, "Internet parenting styles and the impact on Internet use of primary school children," Computers \& Education, vol. 55, pp. 454-464, 2010.

[14] Y. Li, "Theories in online information privacy research: A critical review and an integrated framework," Decision Support Systems, vol. 54, pp. 471-481, 2012.

[15] M. Álvarez, A. Torres, E. Rodríguez, S. Padilla, and M. Rodrigo, "Attitudes and parenting dimensions in parents' regulation of Internet use by primary and secondary school children," Computers \& Education, vol. 67, pp. 69-78, 2013.

[16] A. Almogbel, M. Begg, and S. H. Wilford, "Analysis of the relationship between Saudi Arabia parents' education and economic level parental control of internet usage," 2015.

[17] P. Nikken and J. Jansz, "Parental mediation of young children's Internet use," EU Kids Online, 2011.

[18] G. Anderson, D. Ktoridou, N. Eteokleous, and A. Zahariadou, "Exploring parents' and children's awareness on internet threats in relation to internet safety," Campus-Wide Information Systems, vol. 29, pp. 133-143, 2012.

[19] C. Ponte and J. A. Simões, "Asking parents about children's internet use: comparing findings about parental mediation in Portugal and other European countries," in EU Kids Online-Final Conference. London, 2009.

[20] V. Venkatesh and F. D. Davis, "A theoretical extension of the technology acceptance model: Four longitudinal field studies," Management science, vol. 46, pp. 186-204, 2000.

[21] Mariam Al-Khalifa, Shaheen Khatoon, Azhar Mahmood, and I. Fatima, "Factors Influencing Patients ${ }^{\text {se }}$ Attitudes to Exchange Electronic Health Information in Saudi Arabia: An Exploratory Study," International Journal of Advanced Computer Science and Applications, vol. 7, pp. 197204, 2016.

[22] A. Vance, M. Siponen, and S. Pahnila, "Motivating IS security compliance: insights from habit and protection motivation theory," Information \& Management, vol. 49, pp. 190-198, 2012.

[23] G. Alnajjar, M. Mahmuddin, and R. Thurasamy, "A conceptual model of mobile commerce acceptance in collectivist cultures," presented at the 
Innovation Management and Technology Research (ICIMTR), 2012 International Conference on, 2012.

[24] J. L. Claggett and D. L. Goodhue, "Have IS researchers lost bandura's self-efficacy concept? A discussion of the definition and measurement of computer self-efficacy," presented at the System Sciences (HICSS), 2011 44th Hawaii International Conference on, 2011.

[25] N. Kock, "WarpPLS 5.0 user manual," Laredo, TX: ScriptWarp Systems, 2015.

[26] F. D. Davis, R. P. Bagozzi, and P. R. Warshaw, "User acceptance of computer technology: a comparison of two theoretical models," Management science, vol. 35, pp. 982-1003, 1989.

[27] N. B. Osman, "Extending the Technology Acceptance Model for Mobile Government Systems," development, vol. 5, p. 16, 2013.

[28] R. D. Johnson, "Gender Differences in E-Learning: Communication, Social Presence," Innovative Strategies and Approaches for End-User Computing Advancements, p. 175, 2012.
[29] D. T. Campbell and D. W. Fiske, "Convergent and discriminant validation by the multitrait-multimethod matrix," Psychological bulletin, vol. 56, p. 81, 1959.

[30] J. Recker, Scientific research in information systems: a beginner's guide: Springer Science \& Business Media, 2012.

[31] M. Alshehri, S. Drew, and R. AlGhamdi, "Analysis of Citizens Acceptance for E-government Services: Applying the UTAUT Model," arXiv preprint arXiv:1304.3157, 2013.

[32] S. S. Al-Gahtani, G. S. Hubona, and J. Wang, "Information technology (IT) in Saudi Arabia: Culture and the acceptance and use of IT," Information \& Management, vol. 44, pp. 681-691, 2007.

[33] C. Fornell and D. F. Larcker, "Evaluating structural equation models with unobservable variables and measurement error," Journal of marketing research, pp. 39-50, 1981.

[34] N. Kock, "Using WarpPLS in E-Collaboration Studies: Descriptive Statistics, Settings," Interdisciplinary Applications of Electronic Collaboration Approaches and Technologies, vol. 62, 2013. 